\title{
Pemetaan batuan penyusun candi di bawah permukaan berdasarkan metode geomagnetik studi kasus: cagar budaya candi Songgiriti desa Songgokerto kecamatan Batu kota Batu
}

\author{
Agus Riyanto, Siti Zulaikah*, Daeng Achmad Suaidi \\ Universitas Negeri Malang, Jl. Semarang No. 5 Malang, Jawa Timur, Indonesia \\ *Penulis korespondensi, Surel: siti.zulaikah.fmipa@um.ac.id
}

Paper received: Paper received: 01-01-2022; revised: 15-01-2022; accepted: 31-01-2022

\begin{abstract}
The geomagnetic method is often used in petroleum, geothermal and mineral exploration and can be applied to searching prospect archaeological objects (Siahaan, 2009). Several studies has been used the geomagnetic method to seek for archaeological objects by Ariani (2012) in Losari Temples and Sismanto et al (1997) in Kedulan Temple. In Batu City there is one of the cultural heritage that have not been intact called Songgoriti Temple. So, in this research we expected the existence of temple's rocks using geomagnetic method. The de sign of the research using geomagnetic methods begins with the study of litera ture. This research was conducted with two methods there is calculating the val ue of the magnetic susceptibility of samples Temple's rock using Bartington Susceptibility Meter MS2B and retrieving data field using the Proton magneto meter type ENVI SCINTREX. In the end of this research, we accepted the re sults of the two methods were compared to find out the site rock of temple. In magnetometer data analysis, data is processed using Magpick software, surfer 9.0 software and Mag2dc software. The results of the research show that a local magnetic field patterns of rocks in the area of cultural heritage Songgoriti Tem ple is divided into three parts namely high local magnetic field (yellow to red), the moderate local magnetic field (green to yellow) and low local magnetic field (blue). Furthermore based on five cross-sectional modeling using Mag2dc, we obtained the prediction the site of temple Songgoriti that is the sample number 1 found on the 2 position i.e at coordinates 49S $664547.5 \mathrm{~m} 9130115 \mathrm{~m}$ and coor dinate $49 \mathrm{~S} 664585 \mathrm{~m}$ $9130105 \mathrm{~m}$; sample number 3 found on the 2 position i.e at coordinates 49S 664583m 9130100m and coordinate $49 \mathrm{~S} 664585 \mathrm{~m} 9130100 \mathrm{~m}$; sample number 4 found on the 2 position i.e. at coordinates 49S $664577.5 \mathrm{~m} 9130115 \mathrm{~m}$ and coordinate $49 \mathrm{~S} 664577.5 \mathrm{~m}$ 9130110m; sample number 5 found on the 3 position i.e. at coordinates $49 \mathrm{~S} 664566 \mathrm{~m} 9130095 \mathrm{~m}$, coordinates $49 \mathrm{~S} 664573 \mathrm{~m}$

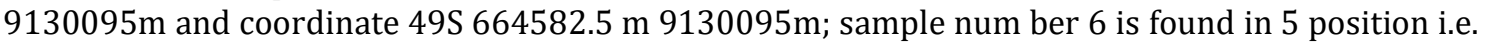
at coordinates $49 \mathrm{~S} 664545.5 \mathrm{~m} 9130110 \mathrm{~m}$, coordinates $49 \mathrm{~S} 664550 \mathrm{~m} 9130110 \mathrm{~m}$, coordinates $49 \mathrm{~S}$ $664546 \mathrm{~m} 9130105 \mathrm{~m}$, coordinates 49S $664565 \mathrm{~m} 9130105 \mathrm{~m}$ and coordinates $49 \mathrm{~S} 664562.5 \mathrm{~m}$ $9130100 \mathrm{~m}$. For sample number 2 that is not found at all in the five models cross section. This may be caused by the value of the magnetic susceptibility sample number 2 is minor when compared to another samples that is $0.86 \times 10-6 \mathrm{~m} 3 / \mathrm{kg}$
\end{abstract}

Keywords: Geomagnetic Methods; Magnetometer; Mapping; Magnetic Susceptibility.

\section{Pendahuluan}

Metode geomagnetik meru pakan salah satu metode geofisika untuk mengukur variasi medan magnetik di permukaan bumi. Metode geomagnetik sering digunakan dalam eksplorasi minyak bumi, panas bumi dan batuan mineral serta bisa diterapkan pada pencarian prospeksi benda-benda arkeologi (Siahaan, 2009). Beberapa penelitian yang pernah dilakukan mengunakan metode geomagnet sebagai pencarian benda benda arkeologi yaitu oleh Ariani (2012) dan Sismanto dkk (1997). Ariani melakukan penelitian "Pemetaan Sebaran Batuan Penyusun Pagar Candi di Situs Candi Losari, Desa Salam, Kecamatan Salam, Kabupaten Magelang Berdasarkan Metode Magnetik". Sismanto dkk melakukan penelitian "Pendugaan Keberadaan Batu Candi di Situs Purbakala Candi Kedulan dari Pola Anomali Medan Magnet Total". 
Di Kota Batu terdapat salah satu cagar budaya berupa candi yang belum utuh yaitu Candi Songgoriti yang terletak di Desa Songgokerto, Kecamatan Batu. Candi ini pertama ditemukan oleh Van I Isseldijk pada tahun 1799. Kemudian pada tahun 1938 dilakukan perbaikan oleh Belanda, tetapi ada kesalahan letak dimana kepala di kaki dan sebaliknya dan akhirnya menjadi puing. Puing puing itupun saat ini sudah tidak di ketahui lagi keberadaannya. (Suwar dono, 2014). Kemungkinan besar keberadaanya yaitu masih terkubur di dalam tanah akibat faktor aktivitas gunung api karena kawasan Songgoriti merupakan daerah yang dikeli lingi oleh rangkaian gunung api seperti Arjuno, Welirang, Kelud, Pan derman, Anjasmoro, dan Kawi (Romdhon, 2013).

Berdasarkan penelitian yang telah dilakukan pada objek penelitian yang memiliki masalah yang sama maka batuan-batuan penyusun situs cagar budaya Candi Songgoriti dapat diketahui letak batuannya menggunakan alat geomagnet sehingga dis usunlah skripsi dengan dengan judul "Pemetaan Batuan Penyusun Candi Berdasarkan Metode Geomagnetik Study Kasus: Cagar Budaya Candi Songgiriti Desa Songgokerto Keca matan Batu Kota Batu”.

\section{Metode}

Penelitian ini dilakukan den gan dua metode yaitu menghitung nilai suseptibilitas magnetik menggunakan Susceptibility Meter Bartington MS2B dan mengambil data lapangan menggunakan magne tometer tipe Proton ENVI SCINTREX. Sebelum melakukan uji suseptibilitas magnetik, terlabih dahulu melakukan pengambilan sampel batuan candi sebanyak 10 sampel batuan di sekitar Candi Songgoriti. Sedangkan untuk pengambilan data geomagnet di area Candi Songgoriti dilakukan pada 65 titik dengan luasan daerah 30 x 15 m2. Dengan bertujuan untuk mendapatkan nilai medan magnet total dan nilai suseptibilitas batuan di bawah permukaan tanah yang akan menggambarkan dimana letak batuan penyusun candi yang masih terkubur. Setelah proses pengambilan data dilakukan, diperlukan beberapa langkah untuk mengolah data untuk kemudian diinterpretasi.

Dalam proses pengolahan data geomagnet, medan magnet lokal adalah medan magnet yang dihasilkan oleh batuan bermagnet yang berada dibawah permukaan bumi dan merupakan target survey. Untuk mendapatkan medan magnet lokal ini, ada beberapa tahap pengolahan data dengan mengguna kan software surfer, software Magpic dan software Mag2dc yang bertujuan untuk mereduksi medan magnet utama dan medan magnet luar. Proses pengolahan data geomagnet dimulai dengan melakukan koreksi harian (diurnal) dan koreksi IGRF untuk mendapatkan medan magnet lokal. Setelah medan magnet terpetakan, langkah selanjutnya

adalah memisahkan anomali medan magnet regional dengan anomali medan magnet lokal dengan melakuakan proses upward continuation untuk menghilangkan efek magnetik lokal yang berada di sekitar daerah yang diteliti. Langkah selanjutnya adalah interpretasi medan magnet lokal untuk mengetahui medan magnet lokal lokasi tersebut. Interpretasi ini dilakukan secara kualitatif dan kuantitatif.

Pada akhirnya hasil dari in terpretasi data geomagnet dibandin gakan dengan data suseptibilitas magnetik sampel batuan. Dari pen cocokan tersebut akan diketahui pre diksi letak batuan candi yang berada dibawah permukaan tanah. Prediksi letak batuan candi tersebut yaitu be rupa titik lokasi dan kedalaman. 


\section{Hasil dan Pembahasan}

Hasil pengukuran suseptibi litas magnetik secara keseluruhan mendapatkan hasil yang baik. Hasil pengukuran suseptibilitas magnetik dari masing-masing sampel ditun jukkan pada table 1 di bawah ini:

Tabel 4.1 Nilai suseptibilitas magnetik sampel batuan

\begin{tabular}{|c|c|}
\hline No. & Nilai Suseptibilitas Sampel Magnetik x 10-6 m3/kg \\
\hline 1 & 9.63 \\
\hline 2 & 0.86 \\
\hline 3 & 2.07 \\
\hline 4 & 4.14 \\
\hline 5 & 14.80 \\
\hline 6 & 38.4 \\
\hline
\end{tabular}

Untuk pengambilan data geomagnet setelah dilakukan koreksi selanjutnya dibuatkan peta kontur menggunakan software surfer 9 yang terdiri dari peta kontur topografi (gambar 1) dan peta kontur medan magnet total (gambar 2) seperti gambar dibawah ini:

\section{Gambar 1 Peta Kontur Topografi}

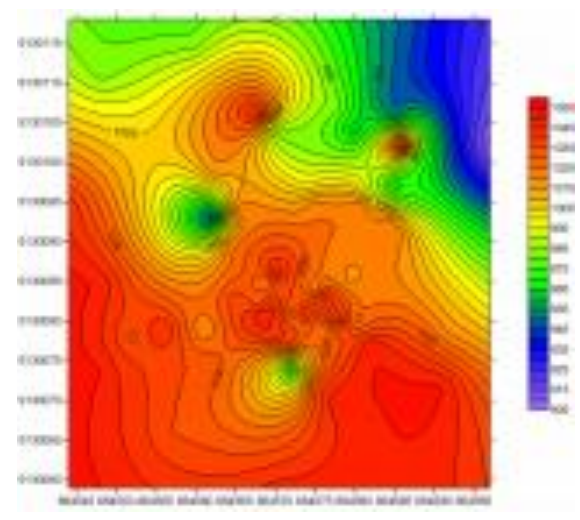

\section{Gambar 2 Peta Kontur Medan Magnet Total}

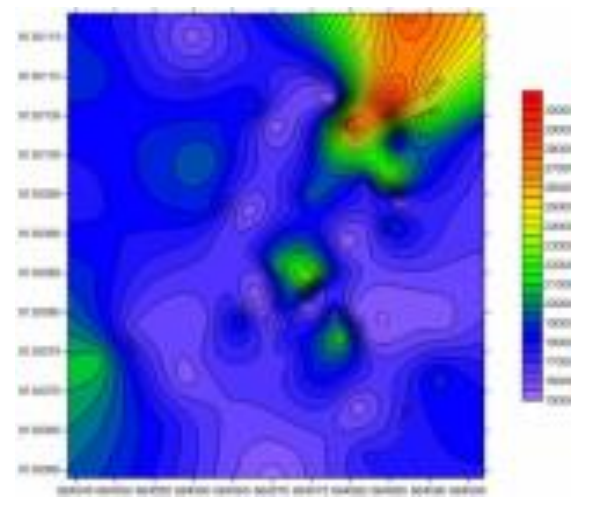

Pada gambar 2 terlihat ada beberapa variasi nilai yang tersebar di daerah penelitian. Dan untuk mempermudah pembacaan kontur di atas, zona medan anomali total dibagi menjadi tiga bagian, yaitu daerah dengan medan magnet total tinggi (di atas $25000 \mathrm{nT}$ ), 
medan magnet total sedang ( 21000 - $25000 \mathrm{nT}$ ), dan medan magnet total rendah (di bawah $21000 \mathrm{nT})$.

Hasil dari pemetaan medan magnet total yang telah dipetakan di atas harus diloreksi dengan koreksi diurnal (harian) dan koreksi IGRF sehingga hasil dari data tersebut adalah benar-benar medan magnet lokal area Candi Songgoriti tersebut. Setelah data diolah dengan koreksi diurnal dan koreksi IGRF maka akan dihasilkan peta medan magnet lokal seperti gambar 3 di bawah ini. Tetapi hasil tersebut merupakan nilai murni dari medan magnet yang ada di daerah penelitian tersebut. Kemu dian dilakukan teknik kontinuasi ke atas (Upward Continuation) untuk benar-benar memperoleh nilai medan magnet dari batuan yang ada diba wah permukaan daerah penelitian. Gambar 4 dibawah ini merupakan hasil dari kontinuasi ke atas (Upward Continuation).

\section{Gambar 3 Medan Magnet Lokal}

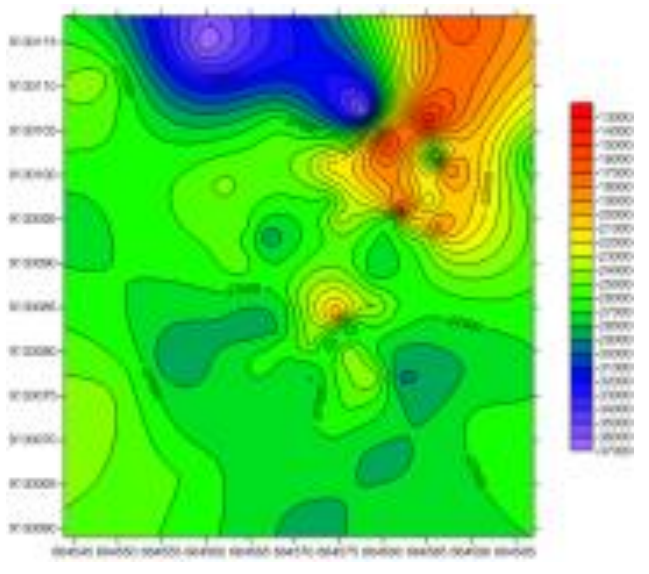

\section{Gambar 4 Medan Magnet Lokal Upward $50 \mathrm{~m}$}

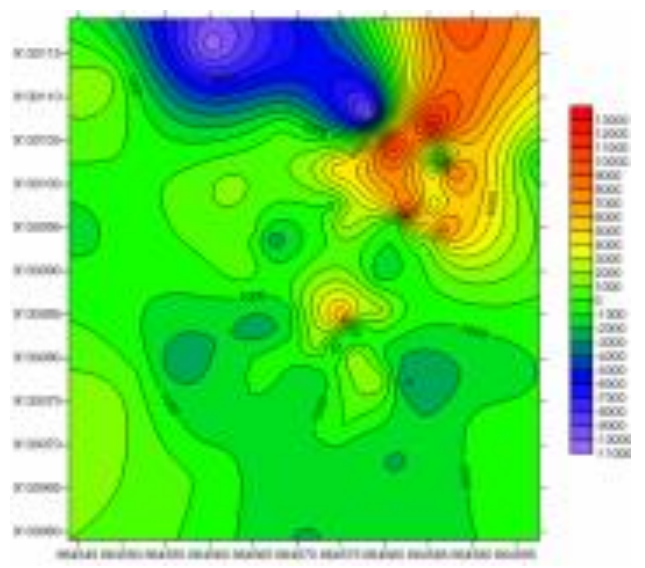

Hasilnya dapat dilihat bahwa pola distribusi medan magnet lokal batuan di area cagar budaya Candi Songgoriti terbagi menjadi tiga bagian: medan magnet lokal tinggi (diwakili dengan warna kuning sampai dengan merah), medan magnet lokal sedang (diwakili oleh warna hijau sampai dengan kuning) dan medan magnet lokal rendah (diwakili oleh warna biru). 
Selanjutnya yaitu melakukan interpretasi data magnetik. Data ter sebut dapat di interpretasikan ke dalam dua cara, yaitu interpretasi secara kualitatif dan interpretasi secara kuantitatif. Interpretasi kualitatif didasarkan pada pola kontur anomali medan magnetik yang bersumber dari distribusi benda-benda termagnetisasi atau struktur geologi bawah permukaan bumi sedangkan interpretasi kuantitatif dilakukan dengan menganalisa peta kontur medan magnetik lokal dengan hasil yang diperoleh dari lokasi benda penyebab anomali magnetik berdasarkan kontur vertikal menggunakan soft ware Mag2dc. Dalam menggunakan software Mag2dc, parameter inputnya adalah sudut deklinasi, inklinasi dan nilai IGRF (medan magnet utama bumi). Pada daerah penelitian ini harga inklinasi dan deklinasi berturut-turut adalah - 32,5886odan 1,1102 odan nilai IGRF (medan magnet utama bumi) adalah 44875,3 nT.

Berikut ini hasil yang diperoleh untuk interpretasi kuanti tatif dari gambar 4 (pembacaannya menggunakan aturan sistem koordinat UTM). Berdasarkan lima pemodelan penampang mengguna kan software Mag2dc diperoleh bahwa (hanya ditampilkan penam pang AB saja):

\section{Gambar 5 Slahing pada kontur medan magnet lokal}

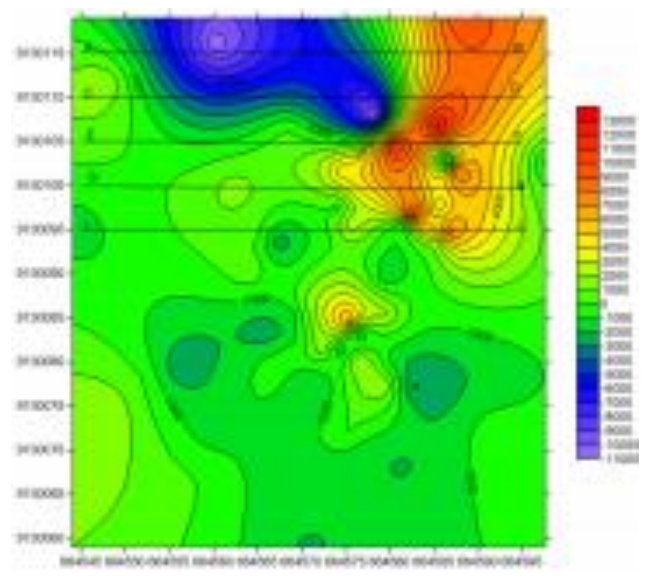

Gambar 6 Pemodelan penampang AB dengan Mag2dc

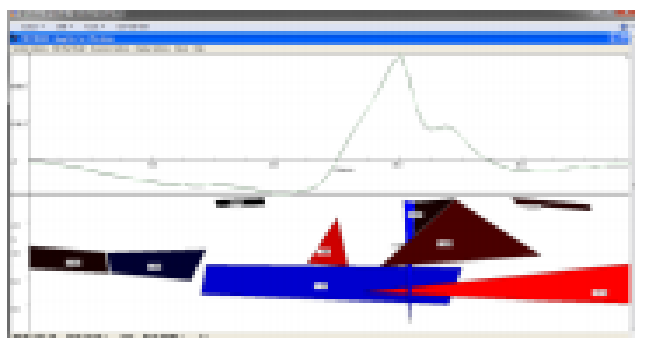




\section{Gambar 7 Pemodelan penampang AB dengan Mag2dc yang disertai table body properties}

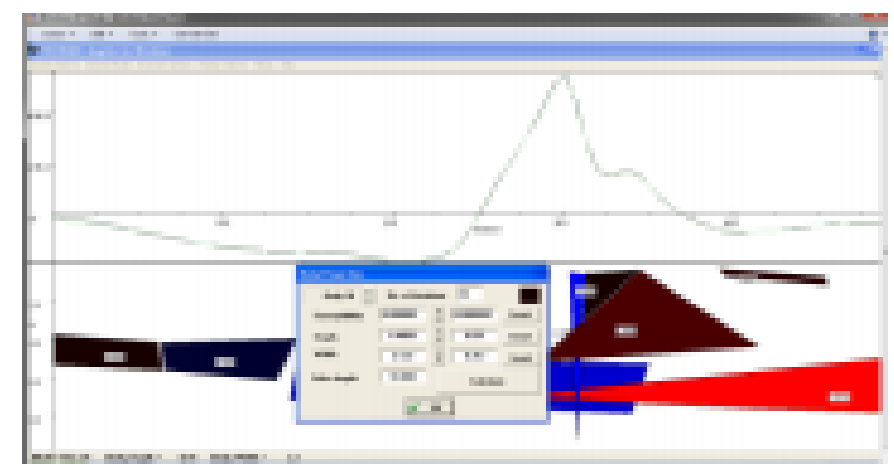

Pemodelan medan magnet lokal penampang melintang AB berada pada kootdinat $49 \mathrm{~S}$ 9130115. Pada pemodelan ini terdapat 10 body. Berdasarkan nilai suseptibilitas magnetiknya, pada pemodelan ini terdapat 2 nilai suseptibilitas sampel batuan candi yang cocok yaitu - Sampel no 1 yang terletak pada jarak 2.5 meter atau pada koordinat 49S $664547.5 \mathrm{~m}$ 9130115m dan pada kedalaman 4 meter dengan nilai suseptibilitasnya sebesar $9.5 \times 10-6 \mathrm{~m} 3 / \mathrm{kg}$. - Sampel no 4 yang terletak pada jarak 32.5 meter atau pada koordinat $49 \mathrm{~S}$ $664577.5 \mathrm{~m} 9130115 \mathrm{~m}$ dan pada kedalaman 1 meter dengan nilai suseptibilitas nya sebesar $5.0 \times 10-6 \mathrm{~m} 3 / \mathrm{kg}$.

\section{Ucapan Terima Kasih (Opsional)}

Husni Cahyadi Kurniawan, S.Si. dan Geophysich team (Prita, Eka, Lutfia, Mayang, Riska, Rosyda, Shelita, dan Yuni) yang telah meberikan bantuan selama penelitian berlangsung.

\section{Simpulan}

\subsection{Kesimpulan}

Berdasarkan hasil penelitian dan pembahasan yang telah dilaku kan di area Candi Songgoriti meng gunakan Magnetometer Proton ENVI SCINTREX dan uji suseptibilitas magnetik menggunakan Susceptibili ty Meter Bartington MS2B, maka dapat diambil kesimpulan sebagai berikut:

4.1.1. Pada penelitian ini, pola distribu si medan magnet lokal batuan di area cagar budaya Candi Songgo riti terbagi menjadi tiga bagian: medan magnet lokal tinggi (di wakili dengan warna kuning sampai dengan merah), medan magnet lokal sedang (diwakili oleh warna hijau sampai dengan kuning) dan medan magnet lokal rendah (diwakili oleh warna bi ru).

4.1.2. Berdasarkan lima pemodelan pe nampang telah diperoleh prediksi letak batuan penyusun candi di cagar budaya Candi Songgoriti, yaitu sebagai berikut:

4.1.2.1.Sampel nomor 1 ditemukan pada 2 posisi yaitu pada koordinat 49S 664547.5m $9130115 \mathrm{~m}$ dan koordinat 49S 664585m 9130105m.

4.1.2.2.Sampel nomor 3 ditemukan pada 2 posisi yaitu pada koordinat $49 \mathrm{~S} 664583 \mathrm{~m}$ 9130100m dan koordinat 49S 664585m 9130100m.

4.1.2.3.Sampel nomor 4 ditemukan pada 2 posisi yaitu pada koordinat $49 \mathrm{~S} 664577.5 \mathrm{~m}$ 9130115m dan koordinat 49S 664577.5m 9130110m. 
4.1.2.4.Sampel nomor 5 ditemukan pada 3 posisi yaitu pada koordinat $49 \mathrm{~S} 664566 \mathrm{~m}$ $9130095 \mathrm{~m}$, pada koordinat $49 \mathrm{~S} 664573 \mathrm{~m} 9130095 \mathrm{~m}$ dan koordinat $49 \mathrm{~S}$ $664582.5 \mathrm{~m} 9130095 \mathrm{~m}$.

4.1.2.5.Sampel nomor 6 ditemukan pada 5 posisi yaitu pada koordinat $49 \mathrm{~S} 664545.5 \mathrm{~m}$ $9130110 \mathrm{~m}$, pada koordinat $49 \mathrm{~S} 664550 \mathrm{~m} 9130110 \mathrm{~m}$, pada koordinat $49 \mathrm{~S}$ $664546 \mathrm{~m} 9130105 \mathrm{~m}$, pada koordinat 49S $664565 \mathrm{~m} 9130105 \mathrm{~m}$ dan koordinat 49S $664562.5 \mathrm{~m} 9130100 \mathrm{~m}$.

Untuk sampel nomor 2 tidak ditemukan sama sekali pada kelima model penampang. Hal ini mungkin disebabkan oleh nilai suseptibilitas sampel nomor 2 yang paling kecil jika dibandingkan dengan kelima sampel lainnya yaitu sebesar $0.86 \times 10-6 \mathrm{~m} 3 / \mathrm{kg}$.

\subsection{Saran}

4.2.1. Untuk penelitian selanjutnya, da lam melakukan uji suseptibilitas harus memperhatikan massa holder sebelum dan sesudah diisi sampel karena masing-masing holder tidak memiliki massa yang sama.

4.2.2. Dalam pengambilan data geo magnetik sebaiknya dilakukan di malam hari untuk menghindari gangguan (noise) dari matahari.

\section{Daftar Rujukan}

ABA, M. U. N., Yulianto, T., \& Harmoko, U. (2014). Interpretasi bawah permukaan daerah sumber air panas diwak-derekan berdasarkan data magnetik. Youngster Physics Journal, 3(2), 129-134.

Anonim (2014, Nopember 25). Magnetik paramagnetik-feromagnetik bab-ii-asmin. https://www.academia.edu/8460392/

Arafah dan Siswanto. (2006). Keberadaan situs pagar dan dinding parit purba pada situs candi plaosan lor di Desa Bugisan, Prambanan, Klaten, Jawa Tengah dengan metode magnetik. Proceeding The 31st Annual Scientific Meeting (PIT) HAGI Semarang: Himpunan Ahli Geofisika Indonesia

Ariani, N. D. (2012). Pemetaan sebaran batuan penyusun pagar candi di situs candi losari dusun losari desa salam Kecamatan Salam Kabupaten magelang berdasarkan metode geomagnetik. http://digilib.uinsuka.ac.id/8114

Dearing, J. (1999). Environmental magnetic susceptibility, using the bartington MS2 system. British Library Cataloguing in Publication Data, ISBN 0952340909.

Eksanti, S. D. (2013). Penerapan metode geomagnet untuk mengetahui nilai suseptibilitas magnetik lapisan tanah dibandingkan dengan pengukuran suseptibilitas magnetik secara langsung: studi kasus lapisan tanah di Desa Pandensari Pujon, Malang (Doctoral dissertation, Universitas Negeri Malang).

Ismail. (2010). Metode geomagnetik. Universitas Sebelas Maret: Surakarta. http://id.scribd.com/doc/40765412/metode-geomagnetik

Rahayu, A. (2012). Status keberlanjutan kota batu sebagai kawasan agropolitan (Doctoral dissertation, Program Magister Ilmu Lingkungan Undip).

Romdhon, S. (2013). Pemetaan potensi geothermal di daerah candi Songgoriti dengan menggunakan metode geomagnet (Doctoral dissertation, Universitas Negeri Malang).

Rosanti, D. F. (2012). Korelasi antara suseptibilitas magnetik dengan unsur logam berat pada sekuensi tanah di Pujon, Malang. Malang: Program Studi Fisika, Fakultas Matematika dan Ilmu Pengetahuan Alam, Universitas Negeri Malang.

Santoso, J. (2002). Pengantar teknik geofisika. Bandung: ITB. Siahaan, B. U. B. 2009. Penentuan. Struktur pada zona hydrokarbon daerah "X" menggunakan metode magnetik. Skripsi: Universitas Indonesia.

Suparwoto, M. (1997). Pendugaan keberadaan batu candi di situs purbakala candi kedulan dari pola anomali medan magnet total. Manusia Dan Lingkungan, 4(1997). 
Jurnal MIPA dan Pembelajarannya, 2(1), 2022, 11-18

Suwardono. (2014, September 24). Korelasi candi songgoriti dengan prasasti sangguran. http://www.wacananusantara.org/korelasi - candi - songgoriti - dengan - prasasti - sangguran - tahun $-928-m$

Syirojudin, M. (2010). Penentuan karakteristik sesar cimandiri segmen pelabuhan rtau-citarik dengan metode magnet bumi. Skripsi: Universitas islam negeri Syarif Hidayatullah Jakarta.

Telford, W.M., Geldart, L.P., dan Sheriff, R.E. (1990). Applied geophysics. Second edition. London: Cambridge University Press. 